\title{
Management pain and anxiety in endodontic treatment
}

\author{
Andi Sumidarti, ${ }^{*}$ Wahyuni S. Dwiandhany
}

CrossMark

\begin{abstract}
Objective: The aim of this paper is to improve the understanding of pharmacology and procedures for pain and anxiety management in endodontic treatment. So, it is important to determine accurate diagnosis, management and drug administration.

Methods: Dental pain is a common symptom that most often causes patient to seek dentist. A survey conducted by the American Association of endodontics revealed that more than half patients who come to dentist have experienced pain, which originate from the teeth or of the
\end{abstract}

surrounding tissue, can causes difficulties in handling, also the anxiety of the patient.

Results: Understanding the pain experienced by patient will help dentist to determine when to make an action. Most patient being fear with pain, so they delay to get treatment from dentist and lead to the development of further infection and inflammation.

Conclusion: Treatment plan includes control of pain before and after determine the effects of drugs that will be recommended for patient.
Department of Conservative Dentistry and Endodontics, Faculty of Dentistry, Hasanuddin University, Makassar, Indonesia
*Correspondence to: Andi Sumidarti, Department of Conservative Dentistry and Endodontics, Faculty of Dentistry, Hasanuddin University, Makassar, Indonesia a_sumidarti@yahoo.com

Received 15 December 2016 Revised 17 December 2016 Accepted 03 January 2017 Available online 01 April 2017

Keywords: Pain, Anxiety, Endodontic treatment

Cite this Article: Sumidarti A, Dwiandhany WS. 2017. Management pain and anxiety in endodontic treatment. Journal of Dentomaxillofacial Science 2(1): 4-6. D0l:10.15562/jdmfs.v2i1.462

\section{Introduction}

One of the goals of endodontic treatment is to prevent and to eliminate pain occurred. During the treatment a lot of patients will feel anxious knowing they will experience pain that obtained during the treatment coupled with inflammatory effects. ${ }^{1,2}$

The use of local anesthetic will reduce and lower the threshold of pain, but the post-treatment pain is common in some procedures, especially in patients who have experienced pain prior to treatment. ${ }^{1,2}$

Some clinicians report that management of the pain experienced by the patient can be a difficult thing, especially during endodontic treatment. Patients who undergo irreversible pulpitis or symptomatic periodontitis experienced central sensitization (increased excitability of neurons beneath the central nervous system ) and peripheral sensitization (decrease threshold and increased response at the end of the peripheral nociseptor). ${ }^{1,3,4}$

Inadequate pain management during endodontic treatment may be caused by changes in the periapical tissues, inflammation or infection of the pulp and apical pathology that can lower the $\mathrm{pH}$ of the tissue in the area around the teeth. ${ }^{5}$ Anxiety to pain arising during endodontic treatment usually associated with treatment procedures and not the post-treatment period. Although control pain in endodontic treatment is not always difficult, but there are a lot of things when the dissatisfaction of patients can not be treated. ${ }^{3}$

The aim of this paper is to improve the knowledge of pharmacology, pain and anxiety management in endodontic treatment.

\section{Methods}

In endodontic treatment, clinician must be able to handle the pain that arises in associated with treatment. According to the survey, most patients being fear with pain, so they delay to get treatment from dentist and lead to the development of further infection and inflammation. ${ }^{3,6,7}$

Common cause of tooth pain generally due to caries, inadequate restoration/defective or trauma, Benders claimed $85 \%$ cases of pain in teeth come from pulp and periapical disease. ${ }^{6}$

\section{Results}

Study by Colleagues for Excellence demonstrate an effective and easy strategies to manage tooth pain in systematic framework or guidelines for the treatment of pain effectively and efficiently named 3D playbook treatment of pain: diagnosis, dental treatment and drugs. ${ }^{6-8}$

1. Diagnosis: process of identifying a disease or 

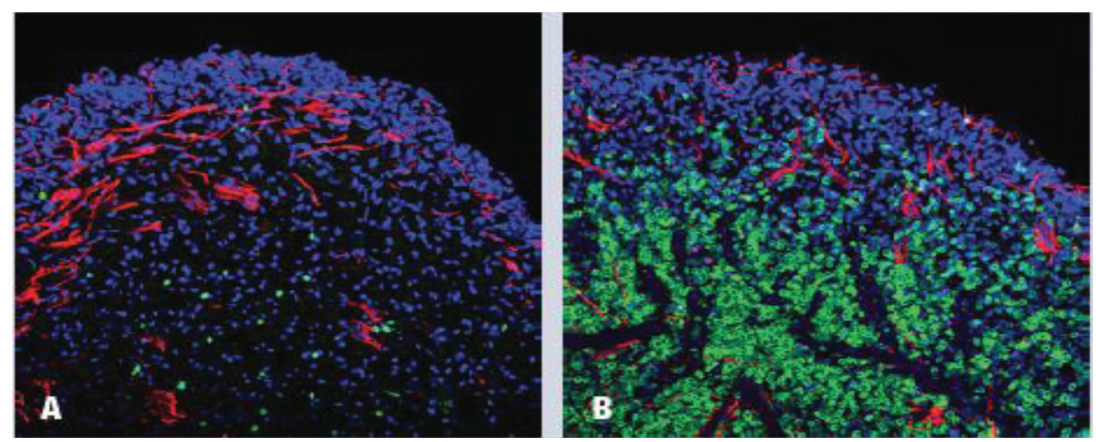

Figure 1 Confocal miscroscopic images normal dental pulp, A. Dental pulp from a patient with a diagnosis of symptomatic irreversible pulpitis, B. Red depicts nerve endings (staining for NFHJ) green depicts leukocytes (CD45) and blue indicates cell nuclei (DAPI).

abnormal condition and collect and evaluate any signs or early symptoms experienced by the patient and yield an investigation. Without a proper, clear/accurate and effective diagnose, clinician can not treat nor provide proper care.

2. Dental treatment: treatment is performed to reduce pain include Root Canal Treatment (RCT) that is effective to reduce pain and discomfort due to increase inflammatory mediators.

3. Drugs: another way to overcoming pain by prescribed analgesics such as NSAIDs and the application of a local anesthetic at least reduce pain before RCT.

Pain and anxiety management in endodontic treatment include: ${ }^{3,6,7}$

1. Psychological approaches include 4C, namely: control, communication, concern and confidence.

2. Control of pain before treatment include: timely and accurate diagnosis as well as lower levels of anxiety.

3. Preoperative non steroidal anti-inflammatory drugs may increase the effectiveness of local anesthesia.

4. Intra-operative pain control include: the effectiveness of the use of drugs/local anesthetic and operative techniques.

\section{Discussion}

Accurate diagnosis and pain control is essential, bear in mind that there is possibility where the pain does not came from the teeth, therefore it is important to know the pain that comes from the teeth and which came from the surrounding tissue. ${ }^{7}$ To determine whether the pain came from the teeth, the first and the most important phase that dentist should be able to notice patient's major complaint by examining the suspect teeth by doing percussion on the tooth with the mouth mirror handle or instrument as tooth slooth or using cold spray, that is important to know the source of the pain comes from the teeth or not.

The treatment to perform include root canal treatment which is considered effective to reduces pain and discomfort that come from inflammation and an increase in the mediators such as bradykinin, prostaglandins and cytokines.

Endodontic treatment on a tooth with irreversible pulpitis and apical periodontitis have higher pain level. Age, gender and length of treatment are factors associated with increase risk of pain experienced during endodontic treatment procedures. ${ }^{1,9,10}$

Pathological inflammation or infection of the pulp and perapical can lower the $\mathrm{pH}$ of the tissue around the teeth. The degree of decrease in $\mathrm{pH}$ tissues surrounding area is varied and decrease $\mathrm{pH}$ will reduce the effects of anesthesia that go into a neural network since more $\mathrm{RNH}+$ ion is formed than $\mathrm{RN}$. RNH+ ions can not migrate through the neural network so the effects of anesthesia also reduced. ${ }^{3}$

One method for obtaining tissue anesthesia in decreasing $\mathrm{pH}$ is by depositing a larger volume of anesthetic on the inflamed area, so we can get larger number of RN inside the neural network. ${ }^{3}$

Anesthetic failure often occurs in endodontic treatment, so the pain management can be solved by minimizing overextention file through the apical foramen in cleaning and shaping stage. Emphasis endodontic instruments beyond the apical foramen can push various irritant to periapical tissue that can cause pain. Some researches suggests that pre-treatment in patients using NSAIDs, inhibit the production and release of inflammatory mediators, therefore it was become effective and comfortable pain management strategy recommended before endodontic treatment., ${ }^{71}$ The combination of pre-treatment NSAIDs using local anesthesia can produce almost $70 \%$ of patients reported no pain or little, even seven hours after treatment.

NSAIDs will inhibit the inflammatory mediators, thereby reducing pain, especially post RCT pain of moderate to severe and a combination of acetaminophen and ibuprofen are the appropriate option to relieve moderate to severe pain after RCT. ${ }^{2}$ However, the clinician should understand that there is contraindications for patients with ulcer, colitis ulcerative, uncontrolled hypertension and patients with renal disease or in the third trimester of pregnancy.

Goals of canal treatment is to prevent or eliminate the pain, although procedures can be done without using local anesthesia. Some studies suggest 
the existence of mild pain post chemo-mechanical preparation, ranged $10-30 \%$ and between visit $14-16 \%$ and reported a correlation between pain and anxiety. ${ }^{2}$

\section{Conclusion}

Pain management caused by inflammation is a common clinical problem, so the effectiveness of pain management begins with determining an accurate diagnosis, treatment plan includes control of pain before and after treatment and determine the effects of drugs that will be recommended for patient.

\section{Conflict of Interest}

The authors report no conflict of interest.

\section{References}

1. Egea SJ, Cabello CR, Carerras LM, et al. Pain associated with rooth canal treatment. Int Endontic J 2009;42: 614-620.

2. Mehrvarzfar PV, Abbott MA, Delvarani SA, et al. Effects of three oral analgesics on postoperative pain following rooth canal preparation a controlled clinical trial. Int Endontic J 2012;46: 76-82.

3. Torabinejad M, Walton RE. Endodontics principle and Preactice. 4th ed. St.Louis: Saunders Elsevier; 2009. p. 129-143.
4. Osbim K, Isbi T, Ogura $\mathrm{Y}$, et al. Clinical investigation of patients who develop neuropathic tooth pain after Endodontic proceducer. J Endo 2009;35: 958-961.

5. Risso AP, Antonio JI, Marcos CP, et al. Postoperative pain and associated factors in adolecent patients undergoing two visit root canal therapy. JC Austra Society Endo 2008;35: 89-92.

6. Cohen S, Burns R. Pathways of the pulp 8th ed. Mosby Elsevier; 2011. p. 40-46.

7. Endodontics colleaques for excellence winter 2015 A"3D" approach for treating acute pain. Chicago: American association of Endodontists; 2015. p. 1-6.

8. Chong BS. Harty's endodontics in clinical practice 6 th ed. Churchill Livingstone Elsevier; 2010. p. 14-15.

9. Moderesi J, Dianat O, Soluti A. Effect of the pulp inflamation on nerve impulse quality with or without anesthesia. JOE 2008;34: 38-41.

10. Pochapski TM, Santos AF, Andrade DE, et al. Effect of preTreatment on postendodontic pain JOE 2009;108: 790-795.

11. Endodontics colleagues for excellence management of acute pain. Chicago: American Association of Endodontists; 1995. p. 1-4

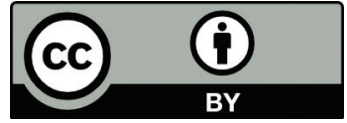

This work is licensed under a Creative Commons Attribution 